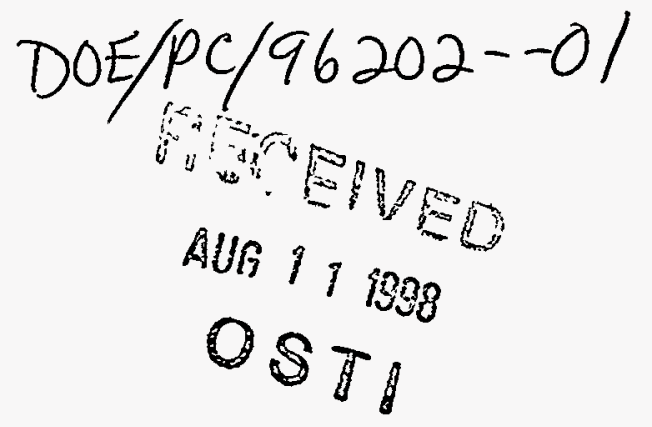

\title{
Electrostatic Surface Structures of Coal and Mineral Particles
}

\author{
Semi-Annual Report \\ September 1, 1996 - March 1, 1997
}

\author{
By: \\ M. K. Mazumder \\ D. Lindquist \\ K. B. Tennal
}

Work Performed Under Contract No.: DE-FG22-96PC96202

For

U.S. Department of Energy

Office of Fossil Energy

Federal Energy Technology Center

P.O. Box 880

Morgantown, West Virginia 26507-0880

By

University of Arkansas at Little Rock

2801 South University

Little Rock, Arkansas 72204

DTOTRIBUTION OF MTE DOCUMENT is UNLMITED

MASTER

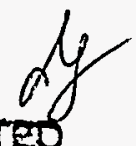




\section{Disclaimer}

This report was prepared as an account of work sponsored by an agency of the United States Government. Neither the United States Government nor any agency thereof, nor any of their employees, makes any warranty, express or implied, or assumes any legal liability or responsibility for the accuracy, completeness, or usefulness of any information, apparatus, product, or process disclosed, or represents that its use would not infringe privately owned rights. Reference herein to any specific commercial product, process, or service by trade name, trademark, manufacturer, or otherwise does not necessarily constitute or imply its endorsement, recommendation, or favoring by the United States Government or any agency thereof. The views and opinions of authors expressed herein do not necessarily state or reflect those of the United States Government or any agency thereof. 


\section{DISCLAIMER}

Portions of this document may be illegible in electronic image products. Images are produced from the best available original document. 


\section{Tribocharging Properties of Coal: UV Photoelectron Spectroscopy (Adam Brown and Nick grable)}

\section{Literature Search (Adam Brown)}

I was recently brought into this program in mid January. I have been assigned to gather literature on tribocharging and UV photoelectron spectroscopy.

A) With regards to tribocharging, I have familiarized myself with the materials Dr. Mazumder has already gathered. I have also reviewed the data gathered here for previous projects and the techniques that where implemented in gathering this data. Collaborating with David Wankum, I have begun to analyze and hypothesis improvements to the tribocharging tests that we currently run.

B) With regards to UV photoelectron spectroscopy (UPS), I began by obtaining two introductory texts.

1) Photoelectron Spectroscopy an introduction to ultraviolet photoelectron spectroscopy in the gas phase by Eland

2) Principles of Ultraviolet Spectroscopy by Rabalais.

These texts are mostly pedagogical in nature and discuss photoelectron spectroscopy performed in a vacuum using an electron detector. While this is not the type of UPS that we hope to perform I believe that the mathematics presented in these texts will be useful in the interpretation 
of data at a later point. These texts present a clear and basic outline of the quantum mechanics and physical chemistry involved in UPS.

When I first arrived Dr. Muzumder provided me with the article, Low-Electron States Related to Contact Electrification of Pendant-Group Polymers: Photoemision and Contact Potential Difference Measurement by Yanagida and Oka. This article presents a method of UPS done in air which can be used to measure the work function of the surface tested and analyze surface charge. To better understand this article I also gathered the following materials listed in the acknowledgments.

1) Charge transfer in metal/polymer contacts and the validity of contact charge spectroscopy by Fabish and Duke.

2) Photo Emission and Contact Charging of Some Synthetic High Polymers by Murata.

3) Externally quenched air counter for low-energy electron emission measurements by Kirhata and Uda.

4) Solid State Surface Science by Green.

As a final addition to my accumulation of materials I have also familiarized myself with what information on UPS present on the 
Internet. The majority of the information on the Internet is about X-ray photoelectron spectroscopy (XPS) which is used to look at the core orbitals of the atoms on the surface of a test material and can be used to penetrate deeper into the test surface than (UPS). The information I found on the Internet is not useful at this point. However, I have marked the locations of test data posted on the Internet which may be useful in later interpretation of data which I will of obtain. I also plan to keep an eye open for new data involving UPS posted on the web.

\section{Instrumentation (Nick Grable)}

The following is a summary of activity on the uv monochrometer:

1) A non-functional Turner Associates Model 430 spectrofluorometer was evaluated for use as a possible uv monochrometer source for low energy photoelectron surface emission measurements. The following problems and corrective measures taken:

a. The 150 watt xenon arc lamp was non-operational. A new ozone-free replacement lamp was ordered from Alpha Source.

b. The ozone-pitted and tarnished elliptical collection mirror and plane folding mirror were demounted and shipped to Lacroix Optical to be recoated. Their preliminary inspection revealed that the elliptical mirror's substrate may need to be repolished prior to recoating with aluminum. 
c. The grating optics module was demounted and inspected.

Because they were shielded from the ozone emissions of the xenon lamp, the plane grating, convex focusing mirror, and folding mirror looked acceptable to use as is.

At this point it looks fairly certain the Turner 430 spectrofluorometer can be made to function as an uv monochrometer. The sample holder will have to be removed and replaced with a suitable relay optic to couple the uv energy from the exit slit to the surface of a photoelectron emitter such as coal. A schematic diagram of the proposed uv monochrometer system is shown in figure 1.

2) As a backup should the Turner monochrometer prove to have inadequate uv throughput for photoelectron emission measurements, two quotations from monochrometer vendors have been obtained:

- Instruments SA Inc. TR180MS1 f/3.9 Monochrometer with 75 watt Xenon Source Module: cost $\$ 8467$.

Spectral Energy Corp. LH-150 quarter meter monochrometer with 150 watt Xenon Illuminator module: cost $\$ 5611$.

After optical components and xenon replacement lamp are received from the vendors, the Turner spectrofluorometer will be reassembled, tested, and calibrated in our laboratory. An opto-mechanical mount to hold exit slit relay optics will be designed and fabricated and/or assembled from 
laboratory components. Commercially available units will be considered if they prove more effective.

A free air photoelectron emission detection system similar to one reported by Kirhata and Uda (Rev. Sci. Inst. 52(1), 1981) is being studied. A literature and vendor search is underway to identify alternative candidate emission detection configurations. 


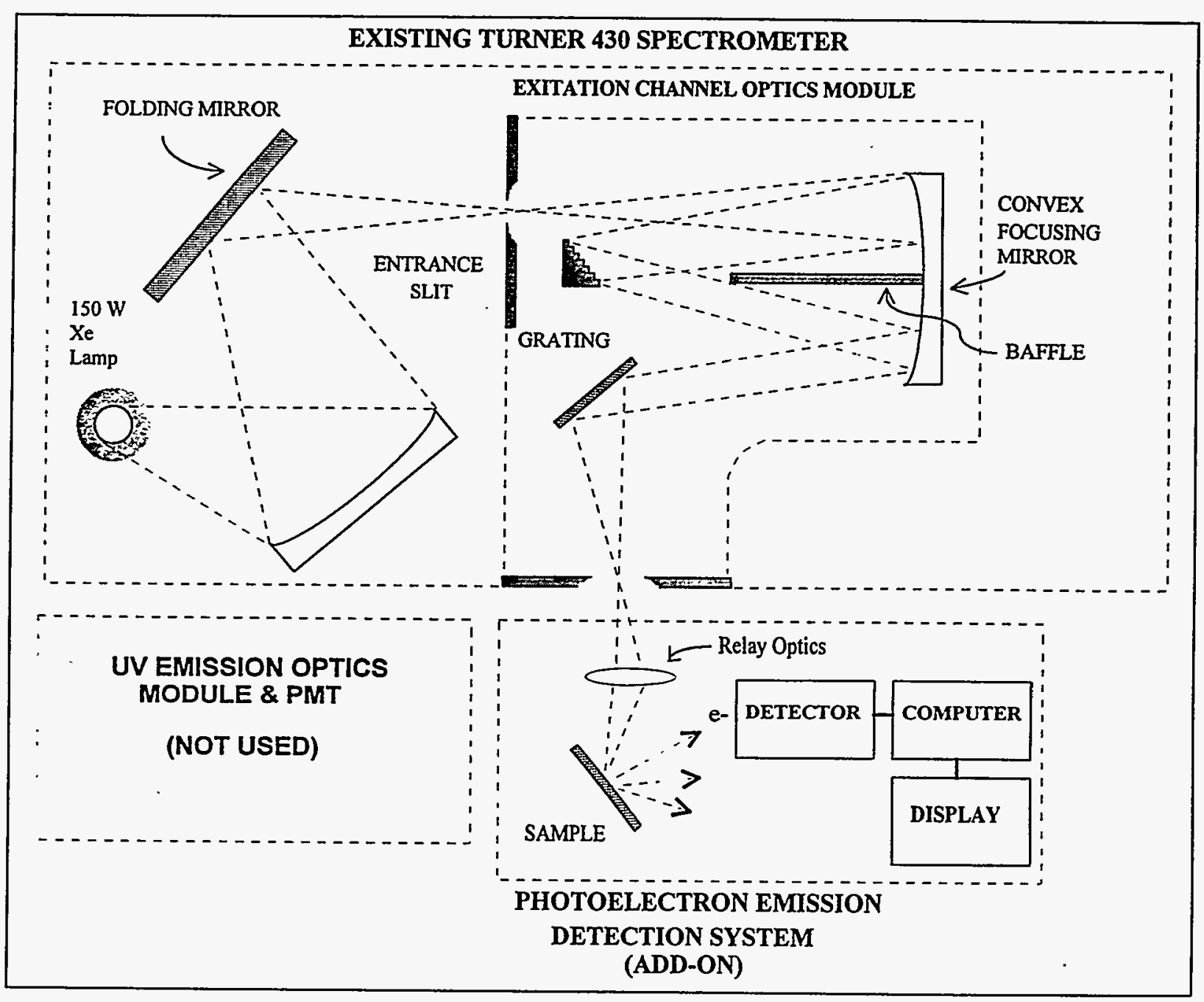

SCHEMATIC OF TURNER 430-003 UV SPECTROFLUOROMETER CONVERTED TO UV MONOCHROMETER 


\section{Electrostatic Separation of Coal as a Function of Particle size Distribution (Jian Zheng)}

\section{PARTICLE SIZE CLASSIFYING}

Experiments for size classifying the coal particles were done by using sieve shakers. Three different kinds shakers was chosen to do the experiment. They were Compressed air shaker, portable sieve shaker and Syntron electronic controller vibrator. Four US standard brass sieves were selected: $45 \mu \mathrm{m}, 106 \mu \mathrm{m}, 150 \mu \mathrm{m}$ and $300 \mu \mathrm{m}$. The block coal was first ground by hand grinder. Then rough coal particles were further ground to fine powder by using "Glenmils". About 50 grams of coal powder were taken to do the size classifying experiment. The powder was being shaken continually for seven minutes for all shaking experiments. The mass of the particles for each size range was weighted after size classifying. And the size distribution of each size range was also analyzed by Mictrotrac particle size analyzer.

The results of mass ratio for each size range are shown Table 1 and Figure 1. It can be seen that the portable sieve shaker is the best for classifying the coal particles among three shakers. About $60 \%$ mass of the total coal particles were separated to smaller size range: $24.3 \%$ in $150 \sim 300 \mu \mathrm{m}, 9.3 \%$ in $106 \sim 150 \mu \mathrm{m}, 19.0 \%$ in 45 
$\sim 106 \mu \mathrm{m}$, and $7.4 \%$ in finest size range. Next is the Syntron electronic controller vibrator. $57.8 \%$ of the total mass was separated from the upper sieve. And the compressed air shaker is the worst. Only about $35.6 \%$ of the total mass was separated.

Table 1. Comparison of particle size classifying efficiency of shakers

\begin{tabular}{|c|c|c|c|}
\hline & \multicolumn{3}{|c|}{ Mass ratio (\%) } \\
\hline $\begin{array}{c}\text { Size } \\
\text { range } \\
(\mu \mathrm{m})\end{array}$ & $\begin{array}{c}\text { Compressed } \\
\text { air shaker }\end{array}$ & $\begin{array}{c}\text { Portable } \\
\text { sieve } \\
\text { shaker }\end{array}$ & $\begin{array}{c}\text { Syntron } \\
\text { controller } \\
\text { vibrator }\end{array}$ \\
\hline$<45$ & 2.1 & 7.4 & 11.4 \\
\hline $45 \sim 106$ & 10.33 & 19.0 & 13.5 \\
\hline $106 \sim 150$ & 7.46 & 9.3 & 8.4 \\
\hline $150 \sim 300$ & 15.6 & 24.3 & 24.5 \\
\hline$>300$ & 64.4 & 40.0 & 42.2 \\
\hline
\end{tabular}

From the particle size distribution analysis (Table 2 and Figures 2), we can also see that larger particles $(>300 \mu \mathrm{m})$ account for about $50 \%$ remaining in upper sieve after separating. It also includes around $50 \%$ particle size in the size range $45 \sim 106 \mu \mathrm{m}$. However, the ratio is low for the other size ranges. The coal powder was first dispersed in water containing small quantity of surfactant and then add to the recirculator reservoir of the instrument. The Mictrotrac calculates particle size distribution based on the diffraction pattern of laser light scatted from the particles. It is probably the smaller particles were coagulated each other to form more larger particles. 
And the coagulated large particles were not easily separated in the water as we prepared samples for Mictrotrac analyzer.

Figure 1 Comparison of particle separating effiency of shakers

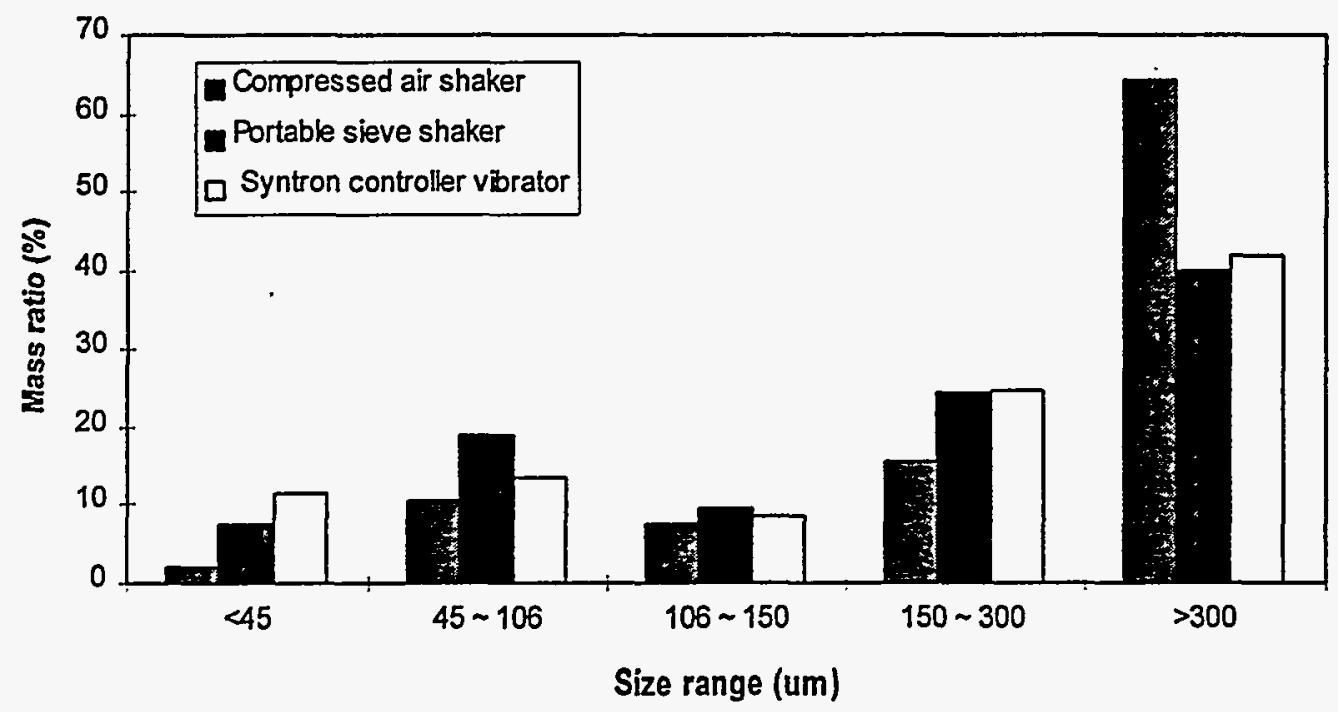

Table 2. Percentage of particles included in the size ranges

\begin{tabular}{|c|c|c|c|}
\hline & \multicolumn{3}{|c|}{ Percentage of particles (\%) } \\
\hline $\begin{array}{c}\text { Size } \\
\text { range } \\
(\mu \mathrm{m})\end{array}$ & $\begin{array}{c}\text { Compressed } \\
\text { air shaker }\end{array}$ & $\begin{array}{c}\text { Portable } \\
\text { sieve } \\
\text { shaker }\end{array}$ & $\begin{array}{c}\text { Syntron } \\
\text { controller } \\
\text { vibrator }\end{array}$ \\
\hline$<45$ & 15 & 10 & 60 \\
\hline $45 \sim 106$ & 51 & 56 & 63 \\
\hline $106 \sim 150$ & 23 & 34 & 32 \\
\hline $150 \sim 300$ & 37 & 34 & 56 \\
\hline$>300$ & 50 & 39 & 60 \\
\hline
\end{tabular}

\section{SEPARATION EFFICIENCY BY DIFFERENT SIZE RANGE}

We have used an electrometer to connect to the tribo-charger to measure the net charge obtained by the coal for each run. And the 
charge over mass value was obtained for each size range. They were $-0.0122 \mu \mathrm{C} / \mathrm{g},-0.00036 \mu \mathrm{C} / \mathrm{g},-0.00022 \mu \mathrm{C} / \mathrm{g},-0.00037 \mu \mathrm{C} / \mathrm{g}$ and $0.00021 \mu \mathrm{C} / \mathrm{g}$ for $<45,45 \sim 106,106 \sim 150,150 \sim 300$, and $>300 \mu \mathrm{m}$ separately. But, the charge over mass ratio for clean coal, refuse and non deposited fractions were not conducted. Table 3 and Figure 3 shows the results of separation efficiency with different size range. It can be seen that percentage of collected mass on negative plate (clean coal) was decreased as the particle size of coal powder increased. It was decreased from about $70 \%$ for particle size smaller than $45 \mu \mathrm{m}$ to $5.8 \%$ for particle size larger than $300 \mu \mathrm{m}$. Similarly, the percentage of collected mass on positive plate (refuse fraction) was also decreased from about $23 \%$ for smaller particles to $0.58 \%$ for larger particles. In comparison, the percentage of non collected particles (deposited on filter) was increased from $0.79 \%$ to $82.1 \%$. Therefore, about $94 \%$ mass of total coal and pyrite can be separated if the particle size ground to less than $150 \mu \mathrm{m}$.

Table 3. Separation efficiency with different coal size

\begin{tabular}{|c|c|c|c|}
\hline & \multicolumn{3}{|c|}{ Mass percentage (\%) } \\
\hline $\begin{array}{c}\text { Size } \\
\text { range } \\
(\mu \mathrm{m})\end{array}$ & $\begin{array}{c}\text { Positive } \\
\text { plate }\end{array}$ & $\begin{array}{c}\text { Negative } \\
\text { plate }\end{array}$ & Filter \\
\hline$<45$ & 23.1 & 70.2 & 0.79 \\
\hline $45 \sim 106$ & 23.6 & 70.9 & 0.37 \\
\hline $106 \sim 150$ & 8.3 & 69.7 & 12.2 \\
\hline $150 \sim 300$ & 3 & 49 & 32.3 \\
\hline$>300$ & 0.58 & 5.8 & 82.1 \\
\hline
\end{tabular}


Figure 2. Percentage of particle included in the size range

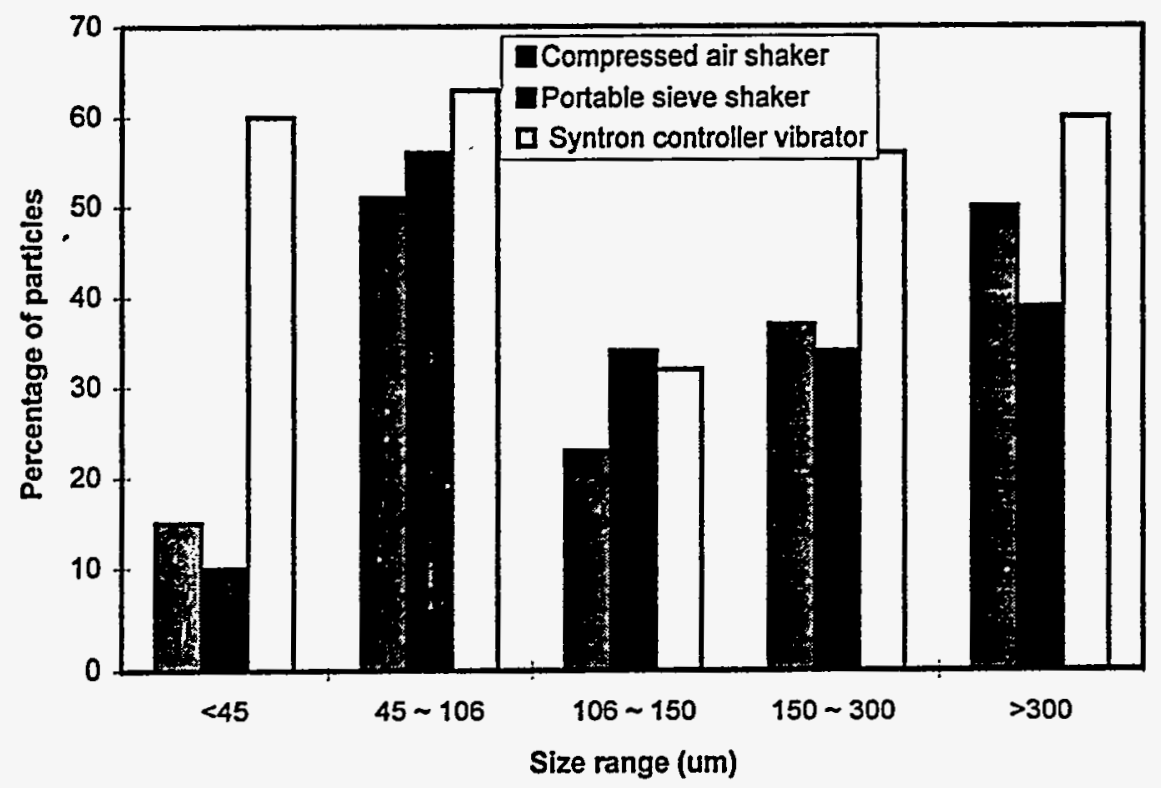

Figure 3. Separation efficiency of coal particles

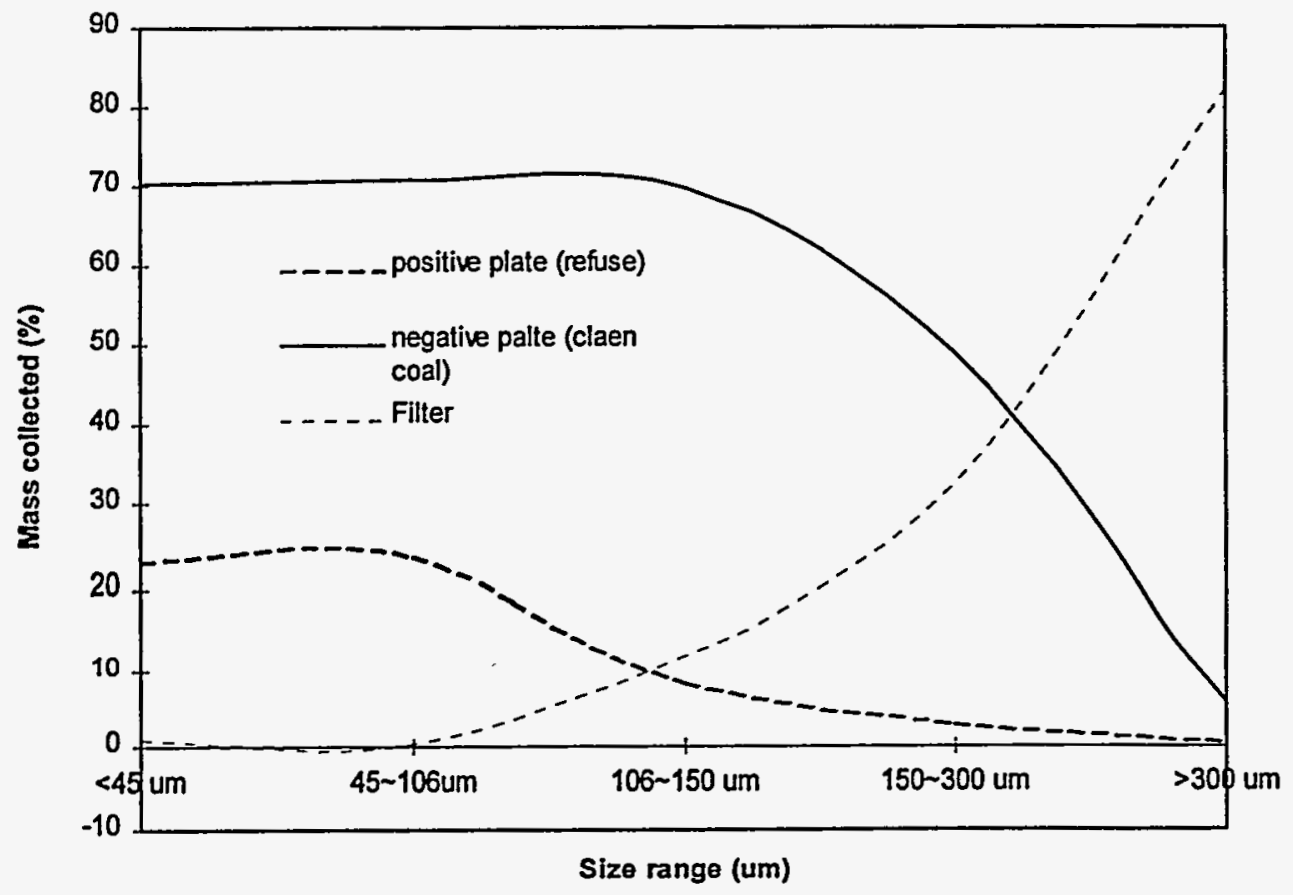




\section{ELECTRODYNAMIC TRAPPING OF CHARGED PARTICLES}

\section{D Electric field simulation}

In last quarterly report, a initial description of design and modeling of toroidal electrode was presented for trapping and measuring single charged particles. A program was written to calculate the $3 \mathrm{D}$ electric field distribution in different location around the toroidal electrode. Figure 4 shows the $3 \mathrm{D}$ electric field on $\mathrm{XOZ}$ plane for $10,000 \mathrm{v}$ applied potential. It can be seen that the electric field on the surface of the. toroidal ring was less than $3 \mathrm{e} 6 \mathrm{v} / \mathrm{m}$. It is possible that the electric field will breakdown if it exceed $3 \mathrm{e} 6 \mathrm{v} / \mathrm{m}$. We suggest to set the applied voltage below $12,000 \mathrm{v}$ to avoid corona discharge for later experiment because it will result in changing the charge properties of the charged particle. Figure 5 shows the $3 \mathrm{D}$ electric field distribution parallel to XOY plane. The electric field above XOY plane is positive. The field is smaller outside the toroid ring. And it is increased as it closer to the edge of the ring. It is highest above the edge of the toroid, and then it decreases again.

\section{Eelectrodynamic force simulation}

From previous discussion, we know that the electricdynamic force on $Z$ axis $\left(F_{z}\right)$ is proportional to $\partial \mathrm{E}^{2} / \partial \mathrm{Z}$. And the electricdynamic force on $\mathrm{Y}$ 
axis $\left(F_{y}\right)$ is proportional to $\partial E^{2} / \partial Y$. The electrodynamic force distribution on $z$ axis is shown in Figure 6 for the toroid of the chosen dimension. The electrodynamic force is largest at $\mathrm{z}=0.003 \mathrm{~m}$. This indicates that particle trapping must occur at $\mathrm{Z}<0.003$ if the particle is to be held. The force is positive from $Z=0$ to $Z=-0.007 \mathrm{~m}$, and is negative from $Z=0$ to $Z=0.007 \mathrm{~m}$. This means that he particle will be trapped if it is located between $Z=-0.007 \mathrm{~m}$ to $Z=0.007 \mathrm{~m}$. From Figure 7 , the electric force is positive on the left side of the ring down to $0.01 \mathrm{~m}$, and negative on the right up to $0.01 \mathrm{~m}$. So the particle is forced to the center of the toroidal ring if it is deviated from center of the toroidal ring. 
Figure $43 \mathrm{D}$ electric field $\left(\mathrm{E}_{-} \mathrm{x}\right)$ distribution on $\mathrm{XOZ}$ plane

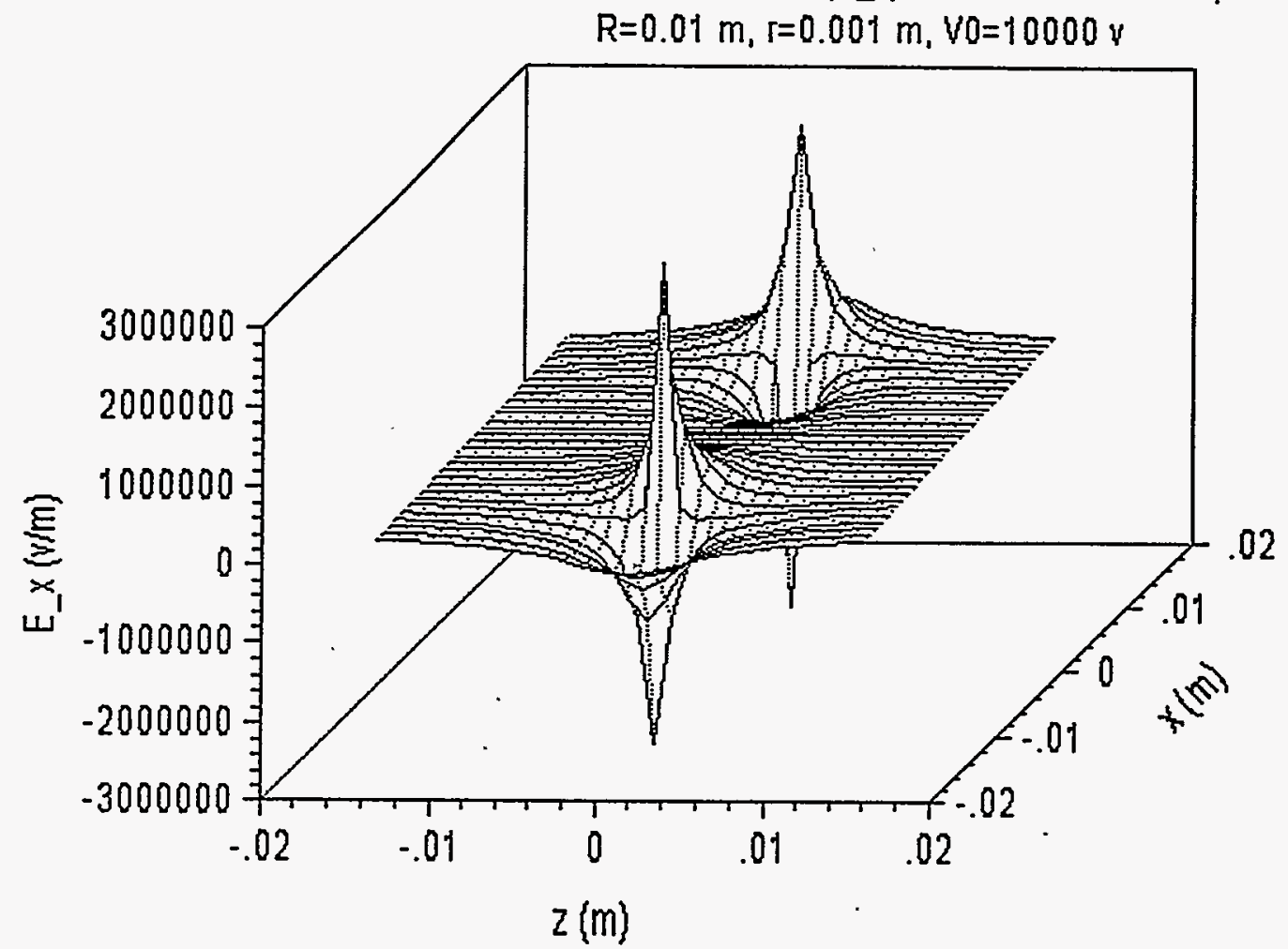

Figure $53 \mathrm{D}$ Electric field distribution on $z=0.007 \mathrm{~m}$ plane $R=0.01 \mathrm{~m}, \mathrm{r}=0.001 \mathrm{~m}, \mathrm{v} 0=10000 \mathrm{v}$.

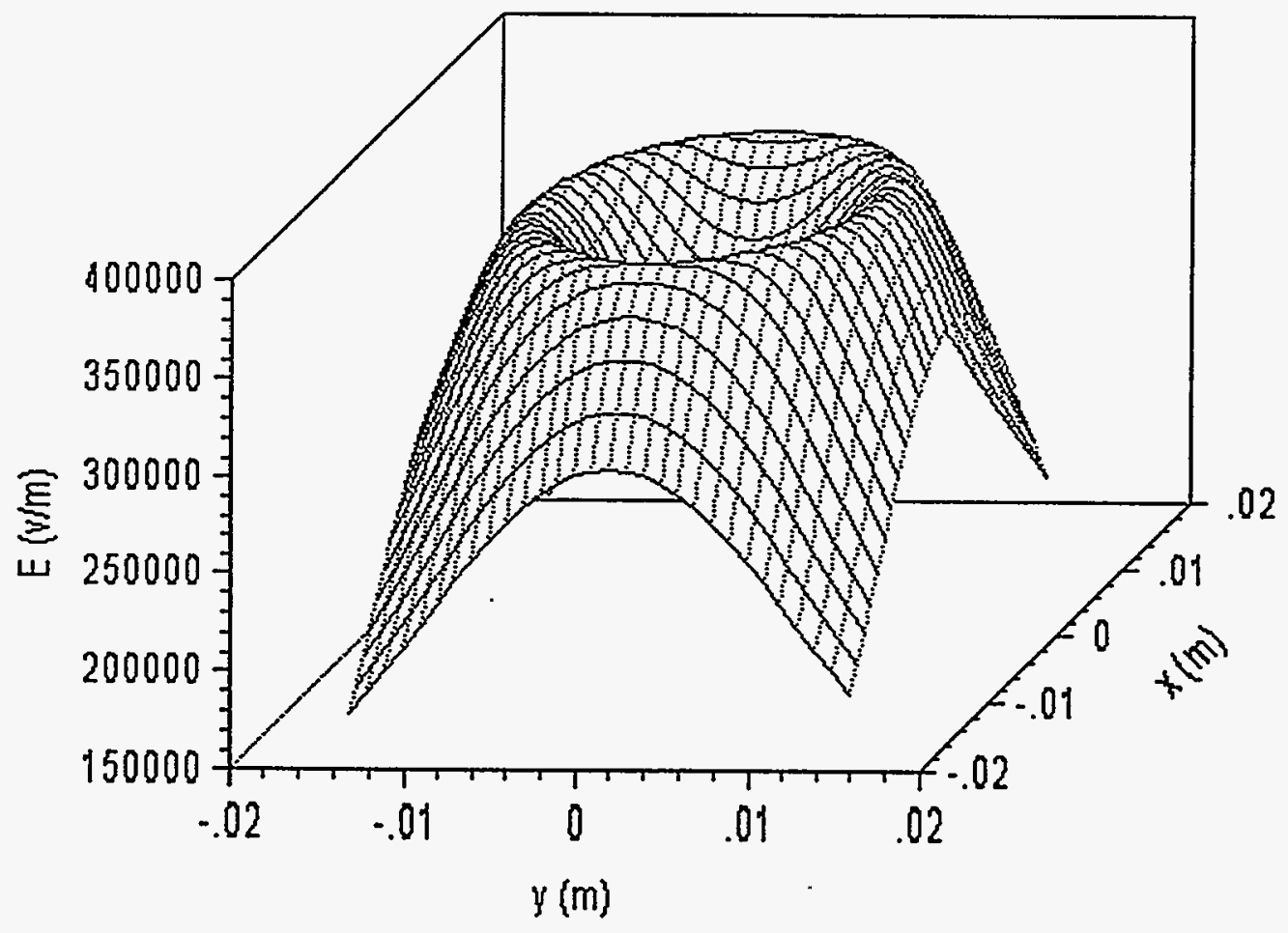



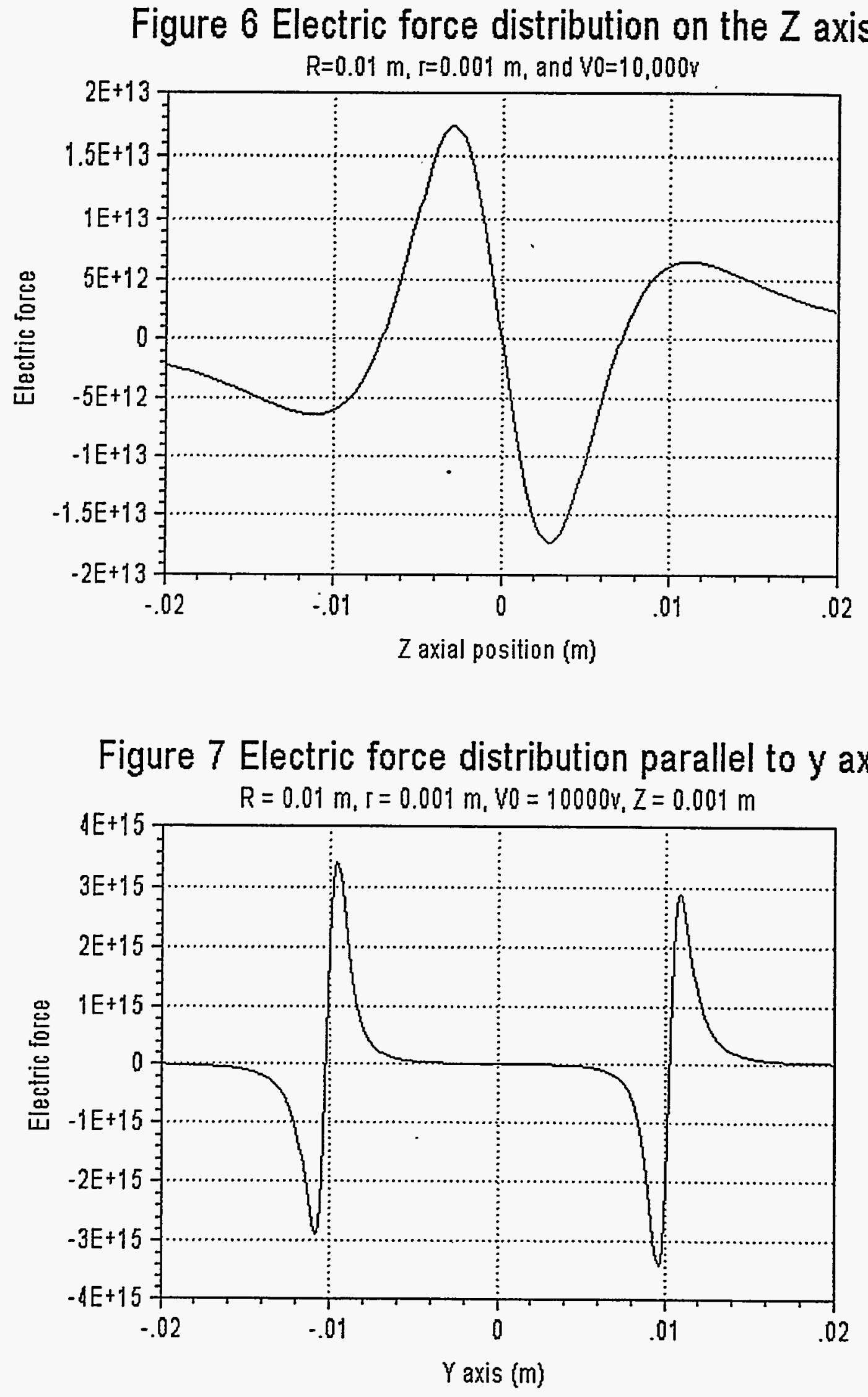


\section{Development of an Image Analyzer for Size and Charge Analysis of Coal Particles (Kevin Tennal and Gan Kok Hwee)}

One goal of the project is to improve instrumentation used to measure the size and charge of particles on an individual particle basis. The instrument used for this purpose has been the E-SPART analyzer. It has had a maximum particle size measurement capability of about 40 microns.

A new instrument for measuring particles using image analysis is being developed to increase the size limit of the measurement to the order of 100 microns. Aerosolized powders are passed between two electrode plates to which a high voltage AC potential is applied. The particles are illuminated by a laser light sheet and the scattered light is collected with a CCD camera. The path of each particle during the integration time of the camera is captured as an image. The paths are sinusoidal tracks the amplitudes of which are a function of the size and charge of the particles. Amplitude modulation of the laser light is synchronized to the phase of the electric field and allows the phase of the particle motion in the electric field to be determined. The initial "proof of concept" prototype of the image analyzer was developed by Ph.D. student Charles $\mathrm{Mu}$ in 1994. Significant modifications have been required to build a practical laboratory instrument. The following information gives some details of the current status of the instrument. 


\section{Laser and Transmitting Optics}

The measurement region is illuminated using two lasers propagating in opposite directions. The use of two lasers instead of one improves the symmetry of the particle images. The lasers are $780 \mathrm{~nm}$ diodes at operated at $20 \mathrm{~mW}$ each. They are set 9.5 inches from the center of the measurement tube. They are focused at the center of the measurement tube after which $+50 \mathrm{~mm}$ cylindrical lenses are placed about two inches from the laser so that the beam is expanded on the vertical axis to about one $\mathrm{cm}$ in height and one $\mathrm{mm}$ thick at the measurement volume. The two lasers are angled slightly downward so that the light from one laser does not enter the other.

\section{Collection Optics}

Two projection lens assemblies placed back to back are used to provide an $\mathrm{f} / 2$ collection system which appears adequate for particles of 5 micron or even smaller. No spherical aberration or coma is evident in the image. The lens system is strapped to the optical table. The size of the measurement volume can be adjusted by moving the lens system along its optical axis. Focussing is done by moving the camera which is mounted to a mechanical $X-Y$ translator. Light shields still remain to be constructed.

Comments: Calculations made using Mie scattering indicated that 
much higher f/number could be used, however measurements with a telemicroscope did not show sufficient light collection for even 20 micron diameter particles.

\section{High Voltage Drive}

The early prototype had significant harmonic distortion in the high voltage. The distortion arose from several sources. Typical neon sign type high voltage transformers have a magnetic shunt designed into them to limit current. This current limiting distorts the voltage profile at the peaks. Also the old system used two transformers in series. We have modified transformers by removing the magnetic shunt and removing primary windings to allow us to use only one transformer. This has improved transformer response.

The HV transformer is driven by a power amplifier. We are currently using a salvaged stereo system power amplifier. We have ordered a new one. Power requirements appear to be low and we may be able to drive the system with a single chip PA. A $20 \mathrm{~W}$ version will be tested this month.

\section{Electrodes}

Curved electrodes, flush with the walls, are used in the sampling tube. This minimizes the disturbance to the air flow. An estimated $2000 \mathrm{~V} / \mathrm{cm}$ field is needed at the sensing volume. For a 45 degree arc 
for the electrodes the field is $1.048 \times$ Potential Difference / $2 \mathrm{r}$ with a variation of less than $0.5 \%$ across the sensing volume. For a 35 degree arc the multiplier is about 0.84 with $1.4 \%$ variation of the field over the sensing volume. The current electrodes have been built with about a 35 degree arc. For this case we need a peak to peak potential difference of $23 \mathrm{KV}$.

\section{Synchronization Circuitry}

In the current design it is necessary to modulate the laser by turning it on for two cycles of the electric drive and then off again. The 'on' time must be synchronized with the phase of the electric drive and must occur when both odd and even fields of the camera's CCD array are integrating for the same frame. Breadboard circuits have been tested and the final circuit board is under construction.

\section{Camera}

A Panasonic video surveillance camera is being used in conjunction with an Imaging Technologies frame grabber. The Camera has a $753 \times 494$ pixel array with a $2 / 3$ inch diagonal format. The frame grabber can digitize and store more than 10 frames per second.

Note that in this application it would be desirable to have a pixel for pixel representation of the CCD sensor response transferred to the computer. This is not obtained with a video camera. A high quality, 
high speed digital camera is out of range of the current budget but would be recommended in the future. In addition analog transfer of the data (video) leads to over and undershoot of the signal following large excursions. This probably has only a small affect on the images but is undesirable. The cost of suitable digital systems is likely to drop significantly in the near future and should be kept in mind.

\section{Analysis of Images}

Each particle track in an image is isolated and fit to a sinusoidal function. Up to ten frames per second can be analyzed with up to about ten particle tracks per frame. The data that must be extracted from the images are the amplitude, phase and spacial frequency of each track. The spacial frequency is simply related to the vertical velocity of the particle. When the flow velocity is known, the settling velocity of a particle can be determined from which its aerodynamic diameter can be

found. Alternatively the aerodynamic diameter can be found from the phase of the track relative to the phase of the electric field. Particles, due to their inertia lag behind the electric field up to a maximum of 90 degrees. The laser is turned on at a zero crossing of the electric field so that a phase reference is present in the recovered image. In the present configuration, phase lag can be used for particles with diameters less than about 30 to 40 microns. For larger particles settling velocity provides a more accurate measure of size. Flow velocity is usually 
determined by measurement of both phase and spacial frequency on particles smaller than about 30 microns. The phase is used to determine diameter from which settling velocity is calculated. The flow velocity is then determined by subtracting the settling velocity from the vertical velocity determined from the spacial frequency. After the size of the particle has been determined its charge can be determined using the amplitude of the sinusoidal track. The equations for calculating settling velocity and for determining particle motion as a function of diameter and charge in the size range 5 to 100 microns are given in an appendix.

\section{Additional Considerations}

1) There is a slight effect on the phase of the particle response due to the settling velocity of the particle when the settling velocity is large enough to require a correction to the drag force based on Reynolds number. When this is the case the horizontal and vertical drag forces are not independent. In a first order approximation of the effect of settling velocity on the phase of particle motion* it was found that failure to account for the change in drag force would cause the size of a 100 micron particle to be underestimated by about $5 \%$. At 70 microns the error is less than $2 \%$ and drops off rapidly for smaller particles. In any case settling velocity and not phase is used to determine particle diameter for particles above 40 microns. The correction is, thus, not required here. In this first order correction the amplitude of particle 
motion is not affected.

*Fuchs' Eq. 10.1 was used for the drag force, where Reynolds number was determined using settling velocity only.

2) Error caused by neglecting the inertial part of the resistance (Fuchs' eq. 19.12 instead of eq. 19.9). Using phase, the diameters of particles with diameters of $100,60,30$, and 20 microns are underestimated by $18 \%, 10 \%, 3 \%$ and $1 \%$, respectively. This correction is easy to make and will be implemented.

3) Counting efficiency. It was previously stated that the counting efficiency would not be dependent on particle size for the conditions 1) the laser is turned on for two cycles of the electric drive, 2) the particle travels no more than the height of the field of view in those two cycles and 3) the particle must be in the field of view for at least one complete cycle.

This is not correct. There is a counting efficiency, CE, associated with the vertical velocity of the particle and the height of the field of view, FOV, given by

$$
C E=F O V /\left[\left(V_{F}+V_{S}\right) \times T_{F}\right],
$$


where $V_{F}$ is the gas flow velocity and $V_{S}$ is the settling velocity of the particle, and $T_{F}$ is the period between laser firings. A relative counting efficiency for particles of two different settling velocities is given by

$$
R C E=\left(V_{F}+V_{S 1}\right) /\left(V_{F}+V_{S 2}\right)
$$

For a field of view of $0.5 \mathrm{~cm}$ and a flow velocity of $10 \mathrm{~cm} / \mathrm{s}$ the counting efficiency is 1.5 for small particles and 0.6 for 70 micron particles (settling velocity of $15 \mathrm{~cm} / \mathrm{s}$ ). This gives an RCE between 5 and 70 micron particles of 2.5. There may also be a bias based on amplitude in the electric field. The RCE's should be the same whether particle generation is continuous or bolus. 


\section{Equations for use with the image analyzer.}

Input parameters should include:

$f$ - frequency of the electric field (cycles/s)

HV - amplitude of electric field (kilovolts - careful about how measured and referenced)

$\rho p$ - particle density (default value $=1000 \mathrm{Kg} / \mathrm{m}^{\wedge} 3$ )

$\chi$ - particle shape factor (default value $=1.00$, this may not be used)

$T$ - temperature in degrees $C$ (default value $=20$ )

DPT - dew point temperature degrees $C$ (defualt value $=0$ )

BP - Barometric pressure (default value $760 \mathrm{~mm} \mathrm{Hg}$ )

Constants include:

$\lambda$ - mean free path of gas molecules $\left(\lambda=0.653 \times 10^{\wedge}-7 \mathrm{~m}\right)$

$\mathrm{g}$ - acceleration due to gravity

$\lambda:=0.653 \cdot 10^{-7} \cdot \mathrm{m} \quad \mathrm{g}:=9.80 \cdot \frac{\mathrm{m}}{\mathrm{sec}^{2}} \quad \rho \mathrm{p}:=1000 \cdot \frac{\mathrm{kg}}{\mathrm{m}^{3}} \quad \mathrm{~T}=20 \quad \mathrm{C} \quad$ DPT $=0 \quad \mathrm{BP}:=760$

$\mathrm{f}=200 \cdot \mathrm{Hz} \quad \chi=1$

Mean free path is used only in the calculation of the slip factor. Variations in $\lambda$ with changing ambient conditions will not significantly affect the slip factor in the particle size range of interest.

Since we are working with fairly dry air at normal room temperatures correction of the viscosity for vapor pressure of water is perhaps not necessary. The viscosity error would be about $2 \%$ for saturated air at $40 \mathrm{C}$ and lower for lower temperatures and lower $\mathrm{RH}$.

$\left.\mathrm{VP}=10^{i} \cdot 3.1411 \cdot 10^{-7} \cdot(\mathrm{DPT})^{3}-1.2500 \cdot 10^{-4} \cdot(\mathrm{DPT})^{2}+0.031561 \cdot(\mathrm{DPT})+0.660514\right]$

Calculate partial pressure of water vapor.

$\rho \mathrm{g}=1.2929 \cdot \frac{\mathrm{BP}-0.3783 \cdot \mathrm{VP}}{760} \cdot \frac{273.13}{273.13+\mathrm{T}} \cdot \frac{\mathrm{kg}}{\mathrm{m}^{3}} \quad$ Calculate gas density.

$$
\rho g=1.202 \cdot \mathrm{kg}^{\circ} \mathrm{m}^{-3}
$$

$\eta=\left(\left(1.78794-\left(4.95 \cdot 10^{-3} \cdot(T-15)\right)\right) \cdot 10^{-5}\right) \cdot \frac{\text { newton } \cdot \sec }{\mathrm{m}^{2}} \quad$ Viscosity at ambient temperature.

$$
\eta=1.813 \cdot 10^{-5} \cdot \mathrm{kg}^{-1} \cdot \mathrm{sec}^{-1}
$$

$\mathrm{MW}=\frac{28.966 \cdot(\mathrm{BP}-\mathrm{VP})+18.00 \cdot \mathrm{VP}}{\mathrm{BP}} \quad$ Average molecular weight of moist air.

$\eta \cdot \eta \cdot \sqrt{\frac{M W}{28.966}}$

$\eta=1.811 \cdot 10^{-5} \cdot \mathrm{kg}^{\cdot} \mathrm{m}^{-1} \cdot \mathrm{sec}^{-1}$
Correction to the viscosity for the reduction in average molecular weight of the gas due to the presence of water vapor. Note that this correction will be very small and could be ignored at temperatures below about $40 \mathrm{C}$ or for dry air.

\section{SETTLING VELOCITY CALCULATION}




$$
\begin{aligned}
& n:=60 \quad r=1.055 \\
& i:=1 \ldots n \\
& d_{i}:=5 \cdot 10^{-6} \cdot r^{i} \cdot m \quad \text { Particle diameter (range for calculation } 1 \text { to } 100 \text { microns) } \\
& C_{i}=1+\frac{2 \cdot \lambda}{d_{i}} \cdot\left(1.257+0.4 \cdot \exp \left(\frac{-1.1 \cdot d_{i}}{2 \cdot \lambda}\right)\right) \quad \text { Cunningham slip correction factor } \\
& K_{i}=\frac{4}{3} \cdot \frac{\left(d_{i}\right)^{3} \cdot \rho p \cdot \rho g \cdot g}{\eta^{2}} \quad \begin{array}{l}
\text { Product of the drag coefficient and the square of the } \\
\text { Reynolds number. }
\end{array} \\
& \mathrm{Vs}_{\mathrm{i}}=\frac{\eta}{\rho g \cdot d_{i} \cdot \chi} \cdot\left[\frac{i}{24}-2.3363 \cdot 10^{-4} \cdot\left(K_{i}\right)^{2}+2.0154 \cdot 10^{-6} \cdot\left(K_{i}\right)^{3}-6.9105 \cdot 10^{-9} \cdot\left(K_{i}\right)^{4}\right] \cdot C_{i} \quad \text { (Eq. VS) }
\end{aligned}
$$

This equation for settling velocity is given in Aerosol Technology by W.C. Hinds (p. 53 of 1982 edition) and is attributed to C.N. Davies. It accounts for the increased drag at high Reynolds numbers while eliminating the specific use of velocity in the correction. I have inserted the shape factor, $\chi$, though this may be a moot point at high Reynolds numbers, since the derivation of $K$ undoubtedly requires spheres. For small particles only the first term in the brackets is important and settling velocity is given by Stokes' law, i.e.

$$
\mathrm{Vs} \cdot=\frac{\rho p \cdot \mathrm{d}^{2} \cdot \mathrm{C}}{18 \cdot \eta \cdot \chi} \text { [don't use this simplified equation] }
$$

The vertical velocity, $\mathrm{Vv}$, of the particle is related to the spatial frequency of the image track by

$$
\mathrm{Vv}_{\mathrm{v}}=\frac{2 \cdot \pi}{\mathrm{w}} \cdot \mathrm{SCF} \cdot \mathrm{fo}_{\mathrm{o}}
$$

where $w$ is the spatial frequency in radians/pixel,

$\mathrm{SCF}$ is the spatial calibration factor in $\mathrm{cm} /$ pixel and

$f$ is the frequency of the electric field.

The settling velocity $\mathrm{Vs}$ of a particle is related to its vertical velocity and the gas flow velocity, Vf, by

$$
V s=V v-V f_{0}
$$

\section{PARTICLE MOTION IN A SINUSOIDAL ELECTRIC FIELD}

The relationship between phase and particle size is given by 
$\tan (\phi)=B r \cdot(2 \cdot \pi \cdot f) \cdot m r o$

where $\mathrm{Br}$ is the reduced mobility and $\mathrm{mr}$ is the reduced mass given by

$$
\begin{aligned}
& \beta_{i}:=\frac{2}{d_{i}} \cdot \sqrt{\frac{2}{2 \cdot \pi \cdot f} \cdot \frac{\eta}{\rho g}} \quad \text { Equations from Fuchs' The Mechanics of Aerosol } \\
& :=\frac{C_{i}}{\frac{9}{4} \cdot\left[\frac{\pi}{6} \cdot\left(d_{i}\right)^{3} \cdot \rho g\right] \cdot(2 \cdot \pi \cdot f) \cdot \beta_{i} \cdot\left(1+\beta_{i}\right)} \quad m_{i}:=\frac{1}{6} \cdot \pi \cdot\left(d_{i}\right)^{3} \cdot \rho p \cdot\left(1+\frac{1}{2} \cdot \frac{\rho g}{\rho p}+\frac{9}{4} \cdot \frac{\rho g}{\rho p} \cdot \beta_{i}\right)
\end{aligned}
$$

Thus

$$
\phi_{i}=\operatorname{atan}\left[B_{i} \cdot(2 \cdot \pi \cdot f) \cdot m r_{i}\right] \cdot \frac{180}{\pi}
$$

From either Eq. VS or Eq. $\phi$ we can generate a lookup table for particle diameter after measuring settling velocity or phase lag.

The velocity amplitude of the particle in the direction of the electric field is

$$
\mathrm{V}_{0}=\frac{\mathrm{q} \cdot \mathrm{E} \cdot \mathrm{Br}}{\sqrt{1+[\mathrm{Br} \cdot \mathrm{mr} \cdot(2 \cdot \pi \cdot \mathrm{f})]^{2}}} \mathrm{~A}:=\frac{1}{2 \cdot \pi \cdot \mathrm{f}} \cdot \frac{\mathrm{q} \cdot \mathrm{E} \cdot \mathrm{Br}}{\sqrt{1+[\mathrm{Br} \cdot \mathrm{mr} \cdot(2 \cdot \pi \cdot \mathrm{f})]^{2}}} 0
$$

After determining diameter we calculate $\mathrm{Br}$ and $\mathrm{mr}$ and combine these with the measurement of amplitude to calulate charge and charge to mass.

$$
\begin{array}{ll}
\mathrm{Br}= & \frac{\mathrm{C}}{3 \cdot \pi \cdot \eta \cdot \mathrm{d}+\frac{3 \cdot \pi}{8} \cdot \mathrm{d}^{3} \cdot \rho \mathrm{g} \cdot(2 \cdot \pi \cdot \mathrm{f}) \cdot \beta} \\
\text { where } \quad \beta=\frac{2}{\mathrm{~d}} \cdot \sqrt{\frac{2}{2 \cdot \pi \cdot \mathrm{f}} \cdot \frac{\eta}{\rho g}} \quad \mathrm{mr}:=\frac{1}{6} \cdot \pi \cdot \mathrm{d}^{3} \cdot \rho \mathrm{p} \cdot\left(1+\frac{1}{2} \cdot \frac{\rho g}{\rho p}+\frac{9}{4} \cdot \frac{\rho g}{\rho \mathrm{p}} \cdot \frac{2}{\mathrm{~d}} \cdot \sqrt{\frac{2}{\omega} \cdot \frac{\eta}{\rho g}}\right) \cdot \\
\mathrm{q}=\mathrm{A} \cdot \frac{\left[1+(\mathrm{Br} \cdot \mathrm{mr} \cdot \omega)^{2}\right]^{\frac{1}{2}}}{\mathrm{E} \cdot \mathrm{Br}}
\end{array}
$$




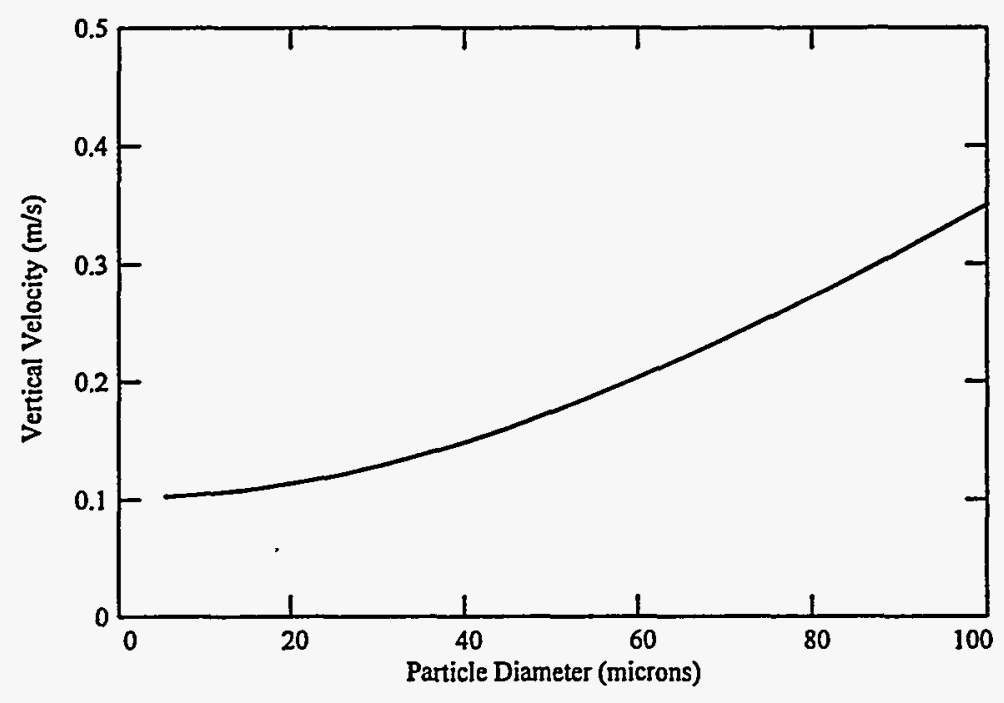

Vertical velocity as a function of aerodynamic diameter for settling due to gravity plus a constant downward airflow of $0.1 \mathrm{~m} / \mathrm{s}$.

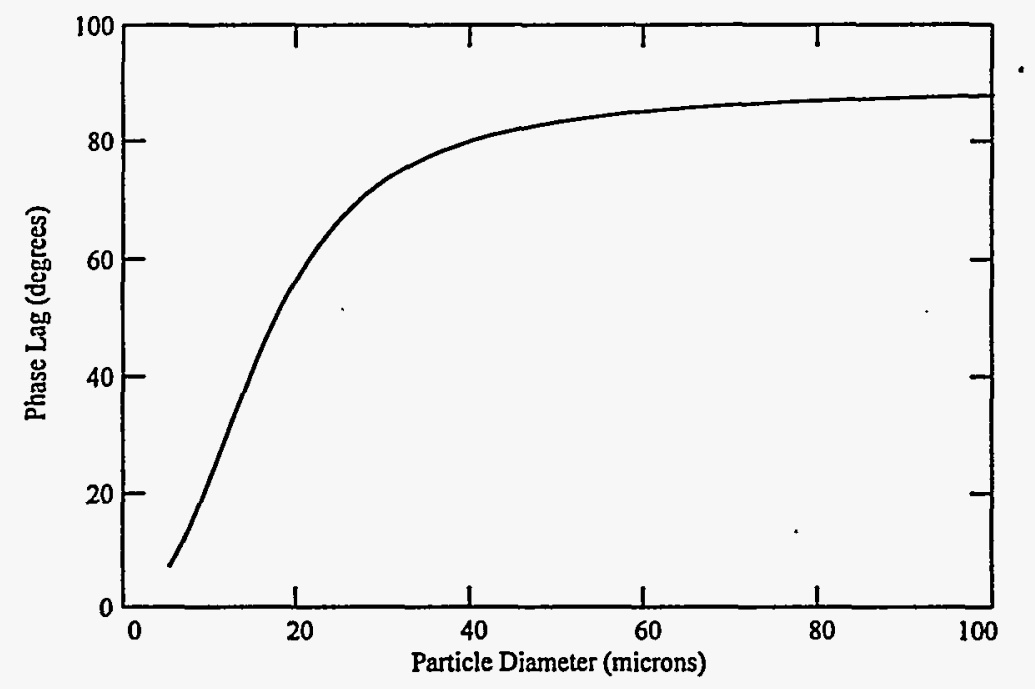

For sizes larger than about 35 microns the phase increases slowly with increasing particle diameter. Hence, a measurement of phase will not accurately determine particle diameter. It is found also 
Hence, a measurement of phase will not accurately determine particle diameter. If Appondix A A p. 5 that the vertical velocity can be determined to high accuracy for most particles. Thus, if the flow velocity is accurately known the settling velocity and the particle size can be accurately determined.

To measure the flow velocity at the view volume we will use phase to determine particle diameter from which we will calculate settling velocity. Air flow velocity is then found by subtracting the calculated settling velocity from the measured vertical velocity which is related to the spatial frequency of the sinusoidal partical track. Only particle tracks meeting specified criteria will be used to estimate flow velocity. Further it will be assumed that the flow velocity does not change rapidly, so that we may go several seconds between particles that meet the criteria.

Criteria for particles used to estimate flow velocity:

Diameter $<25$ micron

Full two cycles

Fit coefficient $>.98$

Flow velocity does not differ too much from previous measurements. 